\title{
Tarla koşullarında doymamış toprak hidrolik iletkenliğinin belirlenmesi ve matematiksel modellenmesi
}

\section{Determination of unsaturated hydraulic conductivity at field conditions and mathematical modeling}

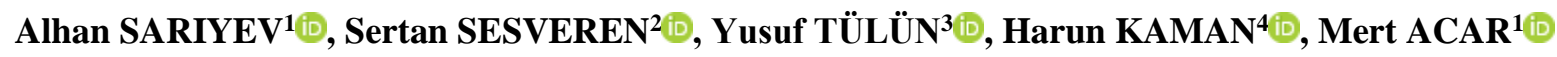 \\ ${ }^{1}$ Çukurova Üniversitesi, Ziraat Fakültesi, Toprak Bilimi ve Bitki Besleme Bölümü, 01330, Adana \\ ${ }^{2}$ Kahramanmaraş Sütçü İmam Üniversitesi, Ziraat Fakültesi, Biyosistem Mühendisliği Bölümü, Avşar Yerleşkesi, 46050, Onikişubat, Kahramanmaraş \\ ${ }^{3}$ Alata Bahçe Kültürleri Araştırma Enstitüsü Müdürlüğü, Erdemli, Mersin \\ ${ }^{4}$ Akdeniz Üniversitesi, Ziraat Fakültesi, Tarımsal Yapılar ve Sulama Bölümü,07059, Antalya \\ Sorumlu yazar (Corresponding author): S. Sesveren, e-posta (e-mail): sesveren@ksu.edu.tr \\ Yazar(lar) e-posta (Authore-mail): asariyev@cu.edu.tr, yusuf.tulun@tarimorman.gov.tr, hkaman@akdeniz.edu.tr, acarmrt.06@gmail.com
}

\section{MAKALE BİLGISI}

Alınış tarihi 07 Şubat 2020

Düzeltilme tarihi 08 Mayıs 2020

Kabul tarihi 19 Mayıs 2020

\section{Anahtar Kelimeler:}

TDR

Serbest drenaj yöntemi

Doygun olmayan hidrolik iletkenlik

Toprak su içeriği

\begin{abstract}
ÖZ

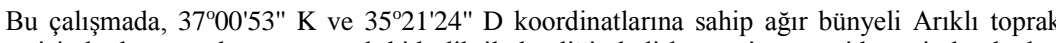
serisinde doygun olmayan toprak hidrolik iletkenliğin belirlenmesi ve arazide yerinde ölçülen ile laboratuvarda ölçülen toprak hidrolik iletkenlik değerlerinin karşılaştırılması amaçlanmıştır. Serbest drenaj altında üzeri PE film ile kapatılmış toprak parsellerinin doygun hale getirilmesi için su uygulanmıştır. Toprak parselleri yaklaşık olarak $2 \times 2 \mathrm{~m}$ boyutlarında oluşturulmuştur. Toprak su içeriği ve matriks emişin zamanla değişimi TDR ve tansiyometre ile izlenmiștir. Arıklı toprak serisine ilișkin hidrolik iletkenlik değeri $0.007-0.652 \mathrm{~cm} \mathrm{sa}^{-1}$ arasında hesaplanmıştır. Toprak-su karakteristiğine ilişkin matematiksel model geliştirilmiş ve model üstel bir fonksiyon ile ifade edilmiştir. Genel olarak, tarla koşullarında gözlemlenen hidrolik iletkenlik $\mathrm{K}(\Theta)_{\mathrm{göz}}$ ile tahminlenen hidrolik iletkenlik $\mathrm{K}(\psi)_{\bmod }$ arasındaki uyum test edildiğinde; kök ortalama kare hatası (RMSE) $0.081 \mathrm{~cm} \mathrm{sa}^{-1}$ ve ortalama mutlak hata (MAE) $0.053 \mathrm{~cm} \mathrm{sa}^{-1}$ ile küçük olmakla beraber ortalama göreceli hata (MRE) değeri \%16.5 ile yüksek bir hata değerine sahip olmuştur. Sonuçlar ayrıca, önerilen yaklaşımın kuru toprak suyu içeriğindeki $\mathrm{K}(\Theta)_{\text {göz }}$ tahminlemesinde doğru olduğunu ortaya koymuştur. Ancak, doygun koşullarda iyi sonuç vermediği gözlemlenmiştir. Sonuç olarak toprak su dinamiği çalışmalarında çalışma yapılacaksa, toprak hidrolik iletkenliğinin belirlenmesinde arazide yerinde ölçümlerin yapılması gerekmektedir.
\end{abstract}

\section{ARTICLE INFO}

Received 07 February 2020

Received in revised form 08 May 2020 Accepted 19 May 2020

\section{Keywords:}

TDR

Free drainage method

Unsaturated hydraulic conductivity

Soil water content

\begin{abstract}
The objective of this study was to determine the unsaturated soil hydraulic conductivity in the heavily structured Ariklı soil series with $37^{\circ} 00^{\prime} 53^{\prime \prime} \mathrm{N}$ and $35^{\circ} 21^{\prime} 24^{\prime \prime} \mathrm{S}$ coordinates and to compare the unsaturated soil hydraulic conductivity measured in the field and laboratory. Water applied to saturate soil plots, which were covered with PE film under free drainage. The soil plots of square shapes had $2 \times 2 \mathrm{~m}$-dimensions. Water content and matric suction of soil with time were monitored by TDR/tensiometer. Arıklı series hydraulic conductivity was calculated as $0.007-0.652 \mathrm{~cm} \mathrm{hr}^{-1}$. The mathematical model of soil-water characteristics was developed and models were expressed by exponential functions. When the agreement between $\mathrm{K}(\Theta)_{\text {obs }}$ observed in field conditions and estimated $\mathrm{K}(\psi)_{\bmod }$ was tested; root mean square error (RMSE) with $0.081 \mathrm{~cm} \mathrm{hr}^{-1}$ and mean absolute error (MAE) with $0.053 \mathrm{~cm} \mathrm{hr}^{-1}$ was small but the mean relative error (MRE) value had a high error value of $16.5 \%$. The results also revealed that the proposed approach was accurate for predicting $\mathrm{K}(\Theta)_{\text {obs }}$ in the dry range of soil water content. However, good results were not obtained in saturation. If the soil-water dynamics studies will be carry out, on-site measurements should be made to determine soil hydraulic conductivity.
\end{abstract}




\section{Giriş}

Toprak hidrolik iletkenliği hidrolojik su döngüsünde önemli bir etkendir. Bundan dolayı topraklardaki su döngüsünün anlaşılmasında değişik toprak özellikleri ile ilişkili olarak hidrolik iletkenliğin sayısal büyüklüğünün belirlenmesi oldukça önemlidir. Toprakların hidrolik iletkenlik özelliğinin bilinmesi kil tipi, toprak sıkışması, toplam porozite, por büyüklük dağılımı, por geometrisi, bünye ve strüktür gibi toprak özellikleri hakkında fikirler vermekte ve çıkarımlar yapılmasına olanak sağlamaktadır (Öztekin ve ark. 2007; Rahimi ve ark. 2011). Ayrıca, toprakların geçirgenlik özelliklerini ve dolayısıyla topraklarda tuz ve tarımsal kimyasalların taşınma ve yıkanmasını kontrol eden önemli fiziksel bir özellik olup, tarım toprakları içinde büyük yersel değişkenlik göstermektedir (Smedema ve Rycroft 1988; Kırda ve Sarıyev 2002). Coğrafi bilgi sistemleri (CBS) ortamında hidrolik iletkenlik tekstür ilişkisini ve hidrolik iletkenliğin toprak profili boyunca (vertikal) değişimi değerlendirildiğinde; özellikle toprak yüzey altı katmanlarında, gözeneklerin boyutuna bağlı olarak tekstürle hidrolik iletkenlik arasında doğru bir ilişki olduğu, yüzey katmanında ise bu ilişkinin yer yer gözlemlendiği belirtilmiştir. $\mathrm{Bu}$ farklılaşmanın; kullanılan amenajman teknikleri, arazi kullanım türleri ve toprakların organik madde içeriğinden kaynaklandığı varsayılmıştır (Özcan ve Akbulut 2006).

Hidrolik iletkenlik ya laboratuvardan toprak örnekleri üzerinde ya da arazide yerinde yapılan denemelerle saptanabilir. Her iki durumda da toprak kitlesinde belirli akış koşulları oluşturulmakta ve daha sonra ölçülen boşalım miktarının hidrolik iletkenlik değeri ile akış koşulları ve boşalım arasındaki ilişkiyi veren eşitlikte yerine konmasıyla hidrolik iletkenlik değeri hesaplanmaktadır (Gemalmaz 1992). Daima arazide yerinde ölçümler tercih edilmekle beraber, ölçüm hataları ve toprağın konumsal değişkenliği elde edilen değerlerin doğruluğunu azaltmaktadır. Yeteri doğrulukta bir hidrolik iletkenlik değeri için de, çok fazla emeğe ve zamana ihtiyaç vardır. Suya doymamış toprak hidrolik iletkenliğin ölçülmesinde kullanılabilecek birçok yöntem bulunmaktadır. Toprak-su karakteristik eğrisi (Talsma 1985), parça dağılım eğrilerine ilişkin veriler, infiltrasyon (Youngs 1987) ve suction permeameter (Cook 1991) yöntemleri kullanılabilir. Laboratuvar ölçümleri tarla koşullarındakine göre daha açık ve doğru olduğunu göstermektedir (Zhuang ve ark. 2001). Ancak, laboratuvar koşullarında sabit veya geçiş durumundaki akış koşullarının sağlanması oldukça zordur ve yöntem tarla koşullarını tamamen temsil etmeyebilir (Nandagiri ve Prasad 1996). Laboratuvar ve tarla yöntemlerinde değinilen problemler, teorik yaklaşımların kullanılmasını yaygın hale getirmiştir.

$\mathrm{Bu}$ yaklaşımlar; idealleştirilmiş sınır koşulları altında topraktaki suyun durumu ve hareketi ile ilgili matematiksel kuramlarla çalışmaktadır. Böyle kuramlar yalnız sınırlı yerlerde uygulanmakta ve gerçek tarla koşulları altında yararlı bulunmaktadır. $\mathrm{Bu}$ yöntemlerden biri de serbest drenaj yöntemidir. Rose ve ark. (1965) ve Watson (1966) tarafindan önerilen yöntem kararsız su akısı ve hidrolik iletkenliğin ölçülmesine dayanan ve tarla koşullarında doymamış hidrolik iletkenliğin ölçülmesinde kolaylıkla kullanılabilecek bir yöntemdir. Yöntem yalnız drenaj koşulları altında buharlaşma ve terleme önlendiğinde toprak sslaklığının ve matrik tansiyon profilinin sık sık ve aynı anda ölçülmesini gerektirir (Watson 1966; Reichardt ve ark. 1998). Yöntem, ters modelleme yaklaşımları ile geliştirilebilmiştir. Ters modelleme model kestirimleri ile gözlemlenen veriler arasındaki farkları en aza indirgeyerek doygun olmayan akış koşullarında toprak özelliklerini temsil eden denklemleri kullanır. Ve doygun olmayan hidrolik iletkenliğin en iyi tahminini verdiğine inanilmaktadır (Finsterle ve Faybishenko 1999; Zhang ve ark. 2003).

Son zamanlarda benzer olmayan ortam kavramları (nonsimilar media concepts) için yapılan yaklaşımlar üzerine durulmuştur (Comegna ve ark. 2000; Rahimi ve ark. 2011; Ahmadi ve Sepaskhah 2012). Toprak-su içeriğine bağlı olarak hidrolik iletkenliğin doygun koşullardaki değeri, toprak yapısı ve gözenek özelliklerini kullanan tekniklerle (fiziksel esasl, ampirik esaslı yada analitik) modelleme yapılabilmektedir. Analitik metotların daha güvenilir olduğu ve aynı zamanda geniş alanlarda gerçek koşulları daha iyi yansıttığı söylenebilir (Ahuja ve Williams 1991). Diğer taraftan, Tyler ve Wheatcraft (1989) bu teknikleri kullanmış ve çok yüksek su içeriklerinde gözlem değerleri ile hesaplanmış doygun olmayan toprak hidrolik iletkenlik değerleri arasında oldukça başarılı bir eşleşme sağlandığını, çok düşük su içeriklerinde ise uygun veri kümelerinin oldukça sınırlı kaldığını bildirmişlerdir. Ayrıca, doygun olmayan toprak hidrolik iletkenliğin belirlenmesinde farkl1 ölçeklerde ve yerinde ölçmek amacıyla uygulanabilir modeller vardır. Bunlar, doygun toprak hidrolik iletkenlik esaslı, toprak su içeriği karakteristik eğrisi temeline dayanan (Mualem 1976; van Genuchten 1980), por büyüklük dağılımı, por geometrisine dayanarak (Zhuang ve ark. 2000; Ahmadi ve Sepaskhah 2012; Ahmadi ve ark. 2015) geliştirilmiş ve denenmiştir. Az sayıda olmak üzere, pedotransfer eşitlikler hidrolik iletkenliğin doygun olmayan (Zhuang ve ark. 2001; Mermoud ve Xu 2006) ve doygun koşullardaki değerlerinin tahminlenmesinde de kullanılmıştır (Yakupoğlu ve ark. 2013).

Sonuç olarak bu alanda temel bilgiler ile bunların uygulanabilirliği arasında zorluklar var olabilmektedir. Bu nedenle doygun olmayan durumdaki hidrolik iletkenliğin tarla koşullarında ölçülmesi ve modellenmesi için kullanılabilir duruma gelen çeşitli yöntemlerin test edilmesinde fayda olabileceği düşünülebilir. $\mathrm{Bu}$ çalışmada, günümüzde kullanılabilir durumda olan "serbest drenaj" metodu ile Çukurova Bölgesi Arıklı serisi toprak yapısına ilişkin doygun olmayan hidrolik iletkenlik değerlerinin tarla koşullarında belirlenmesi ve modellenmesi amaçlanmıştır.

\section{Materyal ve Yöntem}

Deneme Çukurova Üniversitesi, Araştırma ve Uygulama Çiftliğinde yer alan Arıklı serisi üzerinde kurulmuş olup, $37^{\circ} 00^{\prime} 53^{\prime \prime} \mathrm{K}$ ve $35^{\circ} 21^{\prime 24}$ " D koordinatlarına sahiptir. Söz konusu geçit seri toprağını tanımlamak amacıyla $0-10,10-20$ ve 20-30 cm derinliklerden bozulmuş ve bozulmamış örnekler alınmıştır. İleride farklı bağıntıların kurulması amacıyla geçit seri toprağına ilişkin bazı fiziksel ve kimyasal analizler yapılmıştır (Çizelge 1ve 2).

Tekstür analizi hidrometre yöntemiyle Bouyoucos (1962)'a göre, tarla kapasitesi (33 $\mathrm{kPa})$ ve solma noktasındaki $(1500 \mathrm{kPa})$ su tutma kapasiteleri, Klute (1986)'e göre, organik madde modifiye edilmiş Lichterfelder yaş yakma yöntemine göre (Schlichting ve Blume 1966) yapılmıştır. Kireç, Scheibler kalsimetresi ile (McLean 1982), \% Total tuz (1:1 toprak-su karışımında elektriksel iletkenliğe bağlı kondaktivite metodu ile (Black 1965), toprak reaksiyonu Beckman $\mathrm{pH}$ metresiyle belirlenmiştir (United States Salinity Labaratory Staff 1954). Alınan bozulmamış toprak örneklerinde makro, mikro ve toplam 
Çizelge 1. Deneme alanı topraklarının bazı özellikleri.

Table 1. Some soil properties of the experimental area.

\begin{tabular}{|c|c|c|c|c|c|c|c|c|}
\hline \multirow{2}{*}{$\begin{array}{l}\text { Derinlik } \\
(\mathrm{cm})\end{array}$} & \multirow{2}{*}{$\begin{array}{l}\text { Organik mad. } \\
\qquad(\%)\end{array}$} & \multirow{2}{*}{$\begin{array}{c}\mathrm{pH} \\
(1: 1)\end{array}$} & \multirow{2}{*}{$\begin{array}{c}\text { Tuz } \\
\%\end{array}$} & \multirow{2}{*}{$\begin{array}{c}\text { Kireç } \\
\%\end{array}$} & Kil & Silt & Kum & Tekstür \\
\hline & & & & & \multicolumn{3}{|c|}{$(\%)$} & sinifi \\
\hline $0-10$ & 1.72 & 7.72 & 0.058 & 38.5 & 44.3 & 37.8 & 17.9 & $\mathrm{C}$ \\
\hline $10-20$ & 1.79 & 7.68 & 0.055 & 38.6 & 43.4 & 36.5 & 20.1 & $\mathrm{C}$ \\
\hline $20-30$ & 1.66 & 7.66 & 0.052 & 38.6 & 43.3 & 36.6 & 20.1 & $\mathrm{C}$ \\
\hline
\end{tabular}

Çizelge 2. Araştırma alanı toprağının 0-30 cm derinlikte bazı fiziksel özellikleri.

Table 2. Some physical properties of the research area soil at a depth of 0-30 cm.

\begin{tabular}{|c|c|c|c|c|c|}
\hline $\begin{array}{l}\text { Derinlik } \\
(\mathrm{cm})\end{array}$ & $\begin{array}{l}\text { Hacim A A }{ }^{-1 r l} 1 \breve{g}_{1} \\
\left(\mathrm{gr} \mathrm{cm}^{-3}\right)\end{array}$ & $\begin{array}{l}\text { Hidrolik İletkenlik } \\
\left(\mathrm{cm} \mathrm{sa}^{-1}\right)\end{array}$ & $\begin{array}{c}\text { Toplam gözeneklilik } \\
(\%)\end{array}$ & $\begin{array}{c}\text { Mikro gözeneklilik } \\
(\%)\end{array}$ & $\begin{array}{c}\text { Makro gözeneklilik } \\
(\%)\end{array}$ \\
\hline $0-10$ & 1.26 & 0.15 & 57.62 & 36.37 & 21.25 \\
\hline $10-20$ & 1.27 & 0.14 & 56.20 & 35.31 & 20.89 \\
\hline $20-30$ & 1.30 & 0.13 & 55.32 & 34.35 & 20.97 \\
\hline
\end{tabular}

gözeneklilik durumu, Danielson ve Sutherland (1986)'e; hacim ağırlığı Blake ve Hartge (1986)'ye göre yapılmıştır.

Toprakların suyu iletme ve geçirgenlik parametresi olan doymuş hidrolik iletkenlik değerleri, Klute ve Dirksen (1986)'in düşen yük metoduna göre aşağıdaki gibi yapılmıştır.

\subsection{Değişken su yükü altında toprak geçirgenliği}

Bozulmamış toprak örnekleri, $100 \mathrm{~cm}^{3}$ çelik silindirde alınmış saf suyla doyurulduktan sonra, çelik silindirin alt ve üst kısımlarına kapaklar yerleştirilmiştir. $100 \mathrm{~cm}^{3}$ boyundaki büret saf su ile doldurulmuş ve büretin alt ucuna geçirilen borunun havası alınarak çelik silindirin alt kapağına takılarak büretin kayıt edilmiş seviyesinden suyun geçmesi için uygulama başlatılmıştır. Örnekten su çıkışı görüldüğü zaman, büretten düşüş kayıt edilerek, değişken su yükü altında toprak geçirgenliği için kullanılan ilgili formülle $(\mathrm{K}=(\mathrm{a} * \mathrm{~L} / \mathrm{A} * \mathrm{t}) * \mathrm{Ln}$ $\left.\left(\mathrm{H}_{1} / \mathrm{H}_{2}\right)\right)$ toprağın doygunluktaki hidrolik iletkenliği hesaplanmıştır. Yukarıdaki eşitlikte; a: pipet alanı, L: çelik silindirin boyu, A: toprak kesit alanı, t: zaman, $\mathrm{H}_{1}$ : pipet su yüksekliği, $\mathrm{H}_{2}$ : düşen su yüksekliğidir.

Laboratuvarda ilgili yöntemle elde edilen sonuçlar ile arazide serbest drenaj yöntemi ile elde edilmiş verilerin karşılaştırılması arazi ve laboratuvar çalışmaları bakımından önem arz etmektedir. $\mathrm{Bu}$ bakımdan teknik olarak yöntemi kısaca açıklamakta fayda vardir:

\subsection{Teorik klsim (serbest drenaj yöntemi)}

Çalışmanın temel yaklaşımını veren teorik eşitlik (1) aşağıda verilmiştir (Kırda ve Sarıev 2002).

$$
\left.K(\bar{\theta})\right|_{z=L}=\left[\frac{d S / d t}{d H / d Z}\right]_{z=L, t}
$$

Eşitlikte;

Ө: Toprak hacimsel su içeriği $\left(\mathrm{cm}^{3} \mathrm{~cm}^{-3}\right) ; \mathrm{S}:$ Kök bölgesinde depolanan su miktarı $\left(\mathrm{cm}^{3} \mathrm{~cm}^{-3}\right)$; H: Toplam hidrolik yük $(\mathrm{cm})$; Z: Toprak derinliği $(\mathrm{cm})$; $\mathrm{K}(\Theta)$ : Toprak hidrolik iletkenliği ( $\left.\mathrm{cm} \mathrm{sa}^{-1}\right)$; t: Zaman (saat).

Burada $d S / d t$ ve $d H / d Z$ sırasıyla, zaman ile eşdeğer su içeriğindeki $\left(\mathrm{cm} \mathrm{sa}^{-1}\right)$ ve derinlik ile hidrolik yükteki $\left(\mathrm{cm} \mathrm{cm}^{-1}\right)$ değişimleri ifade etmektedir.
Serbest drenaj yönteminin uygulanabileceği koşullar altında, tarlada yapılacak ölçümlere ilişkin işlem sırası aşağıdaki gibidir:

1. Yaklaşık $2 \times 2 \mathrm{~m}$ genişliğinde bir tava hazırlanmıştır. Tava kenarlarının 10-15 cm yüksekliğinde bir sırt olarak hazırlanması $\mathrm{su}$ verilmesini kolaylaştırmıştır. TDR probları tavanın merkezine yakın noktalara $15-30 \mathrm{~cm}$ ve $30-60 \mathrm{~cm}$ derinliklere yerleştirilmiştir. Tansiyometreler $15,30,45$ ve $60 \mathrm{~cm}$ 'ye çakılmıştır. Toprağın 60-70 cm derinliği doygun hale getirilecek miktarda parsele su verilmiştir. Tavaya verilmiş olan suyun tamamı infiltre olduktan sonra toprak yüzü plastik bir örtü ile kapatılmış ve böylece toprak yüzeyinden olabilecek buharlaşma (yukarı yöndeki su akısı) önlenmiştir. İlk 2 saat içerisinde özellikle toprak profili drenaj bölgesini (su içeriğinin azaldığı üst katmanları) kapsamak üzere farklı derinliklerde TDR ile toprak su içeriği ölçülmüştür. Ölçüm $\mathrm{t}=0 \mathrm{da}, \mathrm{Z}=10$ veya $Z=15$ $\mathrm{cm}$ derinlikten başlayarak tüm drenaj bölgesini $\left(Z_{0}\right)$ kapsamak üzere yapılmıştır. Tüm drenaj bölgesini kapsayan bir set ölçüm tamamlandıktan sonra yine başa dönülerek yeni bir ölçüm seti başlatılmıştır. 2 saat sürekli ölçüm yapıldıktan sonra yeni ölçüm setleri 30 veya 60 dakika aralıklarla yapılmıştır. Tansiyometre okumaları ilk 2 saat içerisinde her 15 dakika da bir yapılmıştır. Tansiyometre verileri toprak derinliği ve ölçüm zamanını dikkate almıştır. İlk 24 saat içerisinde yapılan ölçümler başlangıçta dakika, saat sonrada gün aralıklarında yapılmıştır. Değişik zamanlarda matrik potansiyel ve su içeriği değerleri, değişik su içeriklerindeki hidrolik iletkenliğin hesaplanması için ölçülmüştür. Denemeye ait aletlerin tarla görünüşü ve şematik diyagramı Şekil 1'de verilmiştir.

2. Akış diyagramı hesaplamalar için hazırlanmış ve kaydedilmiş zamanlarda doygun olmayan toprak hidrolik iletkenlik değişik su içeriklerinde verilmiş olan denklem 1. ile hesaplanmıştır. Doygunluk düzeyi sağlandığında, toprak plastik örtü ile kapatılmıştır. Farklı derinliklerde matrik emiş tansiyometreler ile belirlenmiştir. Toprak su içeriği TDR ile izlenmiştir. Elde edilen veri Excel'de değerlendirilmiştir (Çizelge 3 ve 4).

Aşağıda verilen literatürlerdeki ortak modeller toprak-su özellikleri ve hidrolik iletkenlik için kullanılmıştır (Bondarenko ve ark. 1982; Poluektov 1991; Sarıev ve ark. 2007):

$$
\psi_{m}=\psi_{D} \times E X P \cdot\left(A \times\left(\theta_{D}-\theta\right)\right) \quad(2) \quad K(\psi)=K_{f} \times\left(\psi_{d} / \psi\right)^{m}
$$



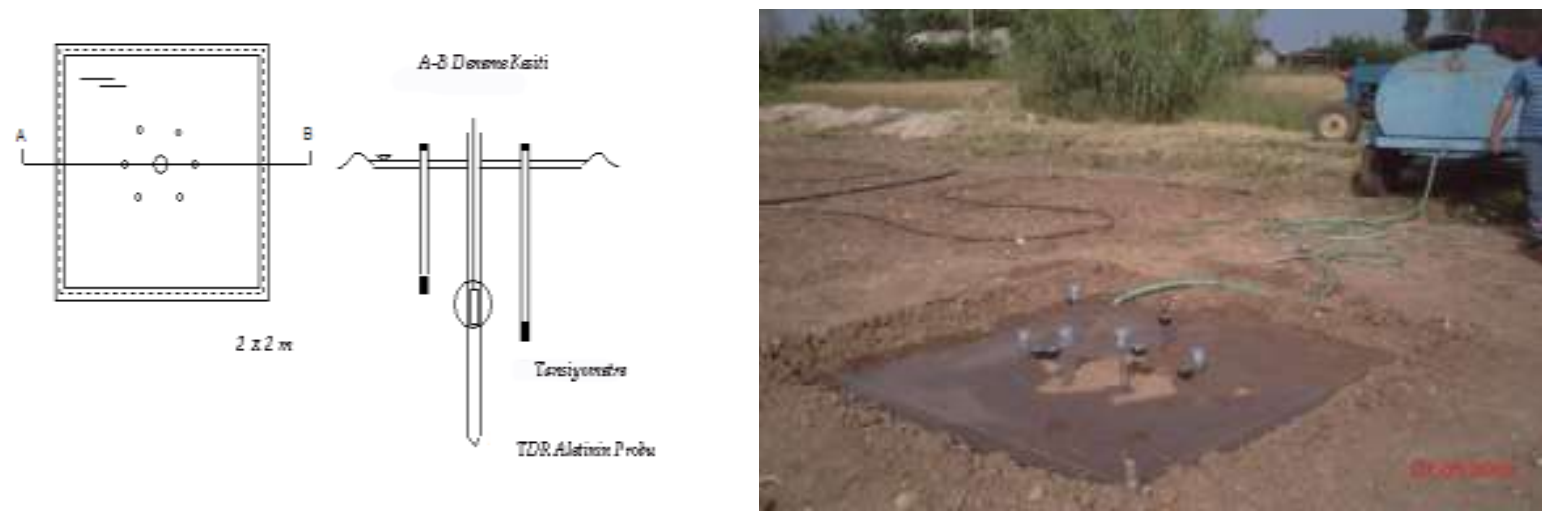

Şekil 1. Deneme parselindeki hidrolik iletkenliğin ölçülmesindeki tansiyometre ve TDR yerleşimi.

Figure 1. Installation of TDR and tensiometers in experimental plot for measuring hydraulic conductivity.

Çizelge 3. Tarla parsellerinde yapılmış olan hidrolik iletkenlik ölçümlerine ilişkin su içeriği $\left(\theta, \mathrm{cm}^{3} \mathrm{~cm}^{-3}\right)$ ve matrik emiş-toplam hidrolik yük $\left(\Psi_{\mathrm{m}}\right.$, $\mathrm{cm})$.

Table 3. Water content $\left(\theta, \mathrm{cm}^{3} \mathrm{~cm}^{-3}\right)$ and matrix suction or total hydraulic load $(\Psi \mathrm{m}, \mathrm{cm})$ related to hydraulic conductivity measurements made in the field plots.

\begin{tabular}{|c|c|c|c|c|c|c|c|c|c|}
\hline \multirow{2}{*}{ Derinlik (cm) } & \multicolumn{9}{|c|}{ Zaman (saat) } \\
\hline & $\mathbf{0}$ & 1 & 2 & 3 & 24 & 48 & 72 & 96 & 120 \\
\hline & \multicolumn{9}{|c|}{ Su içeriği $\left(\theta, \mathrm{cm}^{3} \mathrm{~cm}^{-3}\right)$} \\
\hline 20 & 0.51 & 0.50 & 0.49 & 0.47 & 0.45 & 0.44 & 0.43 & 0.42 & 0.40 \\
\hline 30 & 0.50 & 0.49 & 0.47 & 0.46 & 0.43 & 0.42 & 0.41 & 0.40 & 0.39 \\
\hline \multirow[t]{2}{*}{40} & 0.48 & 0.47 & 0.47 & 0.46 & 0.42 & 0.42 & 0.40 & 0.39 & 0.37 \\
\hline & \multicolumn{9}{|c|}{ Matrik emiș $\left(\Psi_{\mathrm{m}}, \mathrm{cm}\right)$} \\
\hline 15 & & 12 & 13 & 14 & 40 & 72 & 101 & 135 & 130 \\
\hline 30 & & 18 & 20 & 35 & 58 & 89 & 135 & 180 & 220 \\
\hline 45 & & 32 & 34 & 50 & 69 & 100 & 148 & 190 & 231 \\
\hline $40 \mathrm{~cm}$ için hesaplanmış değer & & 27.3 & 29.3 & 45.0 & 65.3 & 96.3 & 143.6 & 186.7 & 227.3 \\
\hline
\end{tabular}

Çizelge 4. Toprağın $Z=40 \mathrm{~cm}$ derinliğinde yapılan hidrolik iletkenlik hesaplamalarının özeti.

Table 4. Summary of hydraulic conductivity calculations made at soil depth of $Z=40 \mathrm{~cm}$.

\begin{tabular}{|c|c|c|c|c|c|c|c|c|c|}
\hline \multirow[b]{2}{*}{ Zaman (saat) } & \multicolumn{9}{|c|}{ Hidrolik iletkenlik $\left(\mathrm{K}, \mathrm{cm} \mathrm{sa}^{-1}\right)$} \\
\hline & $\mathbf{0}$ & 1 & 2 & 3 & 24 & 48 & 72 & 96 & 120 \\
\hline Mean $\theta\left(\mathrm{cm}^{3} \mathrm{~cm}^{-3}\right)$ & 0.500 & 0.490 & 0.480 & 0.465 & 0.438 & 0.430 & 0.418 & 0.408 & 0.390 \\
\hline$q=d S /\left.d t\right|_{z=40}=z^{*}(d \theta / d t)$ & & 0.400 & 0.400 & 0.600 & 0.052 & 0.013 & 0.021 & 0.017 & 0.029 \\
\hline $\mathbf{d H} /\left.\mathbf{d z}\right|_{z=40}$ & & 0.61 & 0.65 & 1.24 & 1.01 & 0.97 & 1.71 & 2.07 & 3.89 \\
\hline $\mathbf{K}(\theta)\left(\mathrm{cm} \mathrm{sa}^{-1}\right)$ & & 0.652 & 0.612 & 0.484 & 0.052 & 0.013 & 0.012 & 0.008 & 0.007 \\
\hline
\end{tabular}

Eşitlik 2'de; $\psi_{m}$ matrik potansiyeli $\left(\mathrm{cm} \mathrm{H}_{2} \mathrm{O}\right) ; \psi_{D}$ doymuş koşullarda su potansiyeli $\left(\mathrm{cm} \mathrm{H}_{2} \mathrm{O}\right)$; A, toprak tekstürüne ilişkin katsayıdır; $\theta_{D}$ doymuş koşullarda toprak hacimsel su içeriğidir $\left(\mathrm{cm}^{3} \mathrm{~cm}^{-3}\right)$ ve $\theta$ ölçüm sırasında toprak hacimsel su içeriğidir $\left(\mathrm{cm}^{3} \mathrm{~cm}^{-3}\right)$. Eşitlik 3'de, $m$ yarı ampirik katsayıdır; $K_{f}$ doymuş durumda hidrolik iletkenliktir $\left(\mathrm{cm} \mathrm{sa}^{-1}\right)$.

Modelin tahminleme doğruluğu, ortalama mutlak hata (MAE), kök ortalama kare hatası (RMSE) ve ortalama göreceli hata (MRE) temel alınarak değerlendirilir:

$$
\mathrm{MAE}=\frac{1}{\mathrm{~N}} \times \sum_{i=1}^{i=N}\left|K_{\theta g o ̈ z}-K_{\psi \bmod }\right|
$$

$$
\begin{aligned}
& \text { RMSE }=\sqrt{\frac{\sum_{\mathrm{i}=1}^{\mathrm{i}=\mathrm{N}}\left(\mathrm{K}_{\theta \mathrm{göz}}-K_{\psi \mathrm{mod}}\right)^{2}}{N}} \\
& \mathrm{MRE}=\frac{100}{\mathrm{~N}} \times \sum_{i=1}^{i=N}\left(\frac{K_{\psi \mathrm{mod}}-K_{\theta g \ddot{o} z}}{K_{\theta g o ̈ z}}\right)
\end{aligned}
$$

Ölçülen $K_{\theta g o ̈ z}$ deneysel olduğu ve modellenen $K_{\psi \bmod }$ toprağın doymamış hidrolik iletkenliği tahmin edildiği durumlarda N, gözlem sayısıdır. Ayrıca, hesaplanan ve tahmin edilen değerler arasındaki doğrusal korelasyonu ölçmek için belirleme katsayısı $\left(\mathrm{R}^{2}\right)$ seçilmiştir. Bununla birlikte, $\mathrm{R}^{2}$ matematiksel modele uyum derecesini yansitır (Nath ve Chattopadhyay 2007). $\mathrm{R}^{2}$ değeri 1 'e ne kadar yakın olursa, model gerçek verilere o kadar iyi uyar. 


\section{Bulgular ve Tartışma}

$\mathrm{K}(\theta)$ değerleri $0.652-0.007 \mathrm{~cm} \mathrm{sa}^{-1}$ arasında değişmiştir (Çizelge 4). Sonradan istenildiğinde hidrolik iletkenliğin toprak su içeriğine bağlı olarak nasıl değiştiğini göstermek üzere üstel bir fonksiyon kullanılabilir veya zamansal boyutta hesaplanmıș ve ölçülmüş hidrolik iletkenlikler arasındaki farklılıklar verilebilir. Şekil 2 incelendiğinde, su içeriğinin doygunluktan tarla kapasitesine doğru ve daha düşük su içeriği düzeylerine gidildikçe (24-120 saat) ölçülen ve modellenen doymamış hidrolik iletkenlik değerleri oldukça yüksek bir doğruluk göstermiştir. $\mathrm{Bu}$, kullanılan ortak modellerin düşük toprak su içeriği aralığında $\mathrm{K}(\theta)$ 'u tahmin edebildiğini ortaya koymaktadır. $\mathrm{Bu}$ nedenle, bu basit ölçeklendirme yaklaşımı $\mathrm{K}(\theta)$ 'nın tarla kapasitesi ve daha düşük su içeriğinde tahmin edilmesinde başarılıdır.

Doygun ve yüksek toprak suyu içeriğinde, modelin, (I) toprak gözeneklerindeki suyun nispeten serbest hareketini etkili bir şekilde dikkate alamayacağını ve (II) muhtemelen diğer toprak yapı parametrelerinin (toprak bünyesi, makro gözenek yap1s1, antropojenik modifikasyon) bu fenomene hâkim olduğu düşünülebilir. Bu durumu bazı araştırıcılar; (I) "Yüksek toprak suyu içeriğinde, iki akışkanlı bir faz sistemi söz konusudur. Bunlar farklı yüzey gerilimi olan su-katı ve su-hava arayüzleri ile sınırlandırılmış su dolu gözeneklerden ibarettir. Dolayısıyla modellerin performansını etkileyen su dolu gözenek alanların farklı geometrilere yol açabilecek olması dikkat çekicidir. Ancak bu, yüksek toprak su içeriği için kalibrasyon ve doğrulama verileri arasındaki uyumsuzluğu ortaya çıkarabilir" şeklinde açıklamaktadırlar (Lebeau ve Konrad 2010; Mohammadi ve Vanclooster 2011; Tokunaga 2011). (II) Sadeghi ve ark. (2011), toprağın hidrolik özelliklerinin ölçeklendirilmesinin performansının toprağın bünyesine ve başlangıçtaki toprak suyu içeriği koşullarına duyarlı olduğunu bildirmiştir. $\mathrm{Bu}$ koşullar altında, toprak bünyesinin bir sınıflandırmasının ve başlangıç koşullarının doğrulamadaki zayıf performansı giderilebileceğini bildirmişlerdir. $\mathrm{Bu}$ yaklaşım, su tutma eğrisine dayalı tahminleme ile birleştirildiğinde (Kosugi ve Hopmans 1998; Sadeghi ve ark.
2011), farklı alanlarda toprak hidrolik özellikleri için sağlam bir temel oluşturabilir.

Arıklı serisine ait toprağın $K_{\theta g o ̈ z}$ ve $K_{\psi \bmod }$ arasındaki hata kriterleri Çizelge 5'te verilmiştir. RMSE, MRE ve MAE sirasiyla $0.081 \mathrm{~cm} \mathrm{sa}^{-1}, \% 16.45$ ve $0.053 \mathrm{~cm} \mathrm{sa}^{-1}$ olarak hesaplanmıştır. RMSE ve MAE değerleri küçük olmakla beraber MRE değeri \%16.5 ile yüksek bir hata değerine sahiptir. Bunun nedeni olarak Şekil 2'ye bakıldığında ilk 24 saat içerisinde doygun su içeriği düzeylerinde $K_{\theta g o ̈ z}$ ve $K_{\psi \text { mod }}$ arasındaki farkın yüksek olması hata payını yükselterek genel hata ortalamasını da artırmıştır.

Çizelge 5. Araştırma alanı toprağına ilişskin doymamış hidrolik iletkenliğinin tahminlenmesinde kullanılan modelin test sürecinde hata kriterleri.

Table 5. Error criteria during testing process of the model for prediction of unsaturated hydraulic conductivity of the research area soils.

\begin{tabular}{ccc}
\hline Hata kriteri & Birim & Değer \\
\hline RMSE & $\left(\mathrm{cm} \mathrm{sa}^{-1}\right)$ & 0.081 \\
MAE & $\left(\mathrm{cm} \mathrm{sa}^{-1}\right)$ & 0.053 \\
MRE & $(\%)$ & 16.45 \\
$\mathrm{R}^{2}$ & $(---)$ & 0.9812 \\
\hline
\end{tabular}

Al-Sulaiman ve Aboukarima (2016) Yapay Sinir Ağları (YSA) modelinin tarımsal toprakların doymamış hidrolik iletkenlik değerlerini tahmin etmede çok doğru olduğunu yaptıkları çalışmadaki RMSE $\left(0.000333251 \mathrm{~cm} \mathrm{~s}^{-1}\right)$, MRE (\%4.184) ve MAE $\left(0.000284699 \mathrm{~cm} \mathrm{~s}^{-1}\right)$ değerleri arasında küçük bir hata ile ifade etmişlerdir.

$\mathrm{Bu}$ çalışmada, hesaplanan ve tahmin edilen değerler arasındaki doğrusal korelasyonu belirleme katsayısı $\left(\mathrm{R}^{2}\right) 0.9812$ olarak belirlenmiştir (Şekil 3). Bu işlem sonucundaki $K_{\theta g o ̈ z}$ ve $K_{\psi \text { mod }}$ arasındaki ilişkiyi sunan denklem ise $\mathrm{K}(\psi)_{\bmod }=0.7829$ $\mathrm{K}(\Theta)_{\text {göz }}+0.0054$ şeklinde türetilmiştir.

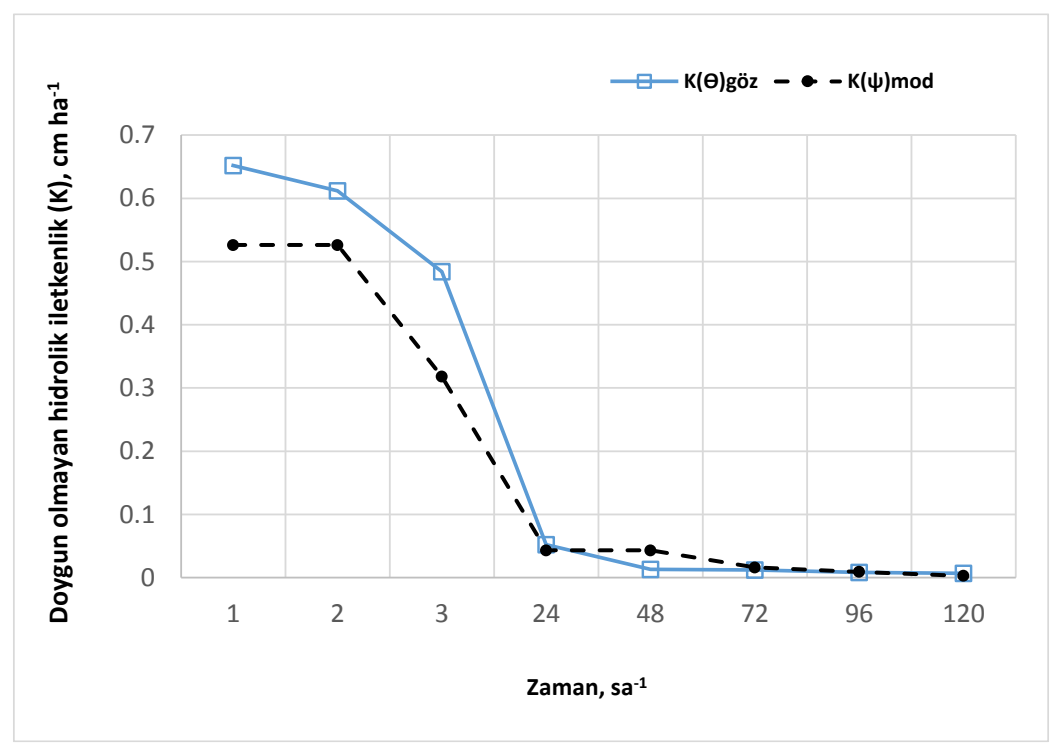

Şekil 2. Zamana göre $K(\theta)_{\text {göz }}$ ve $K(\varphi)_{\text {mod }}$ arasındaki uyum.

Figure 2. Correlation between $\mathrm{K}(\theta)_{\text {obs }}$ and $\mathrm{K}(\phi)_{\bmod }$ over time. 


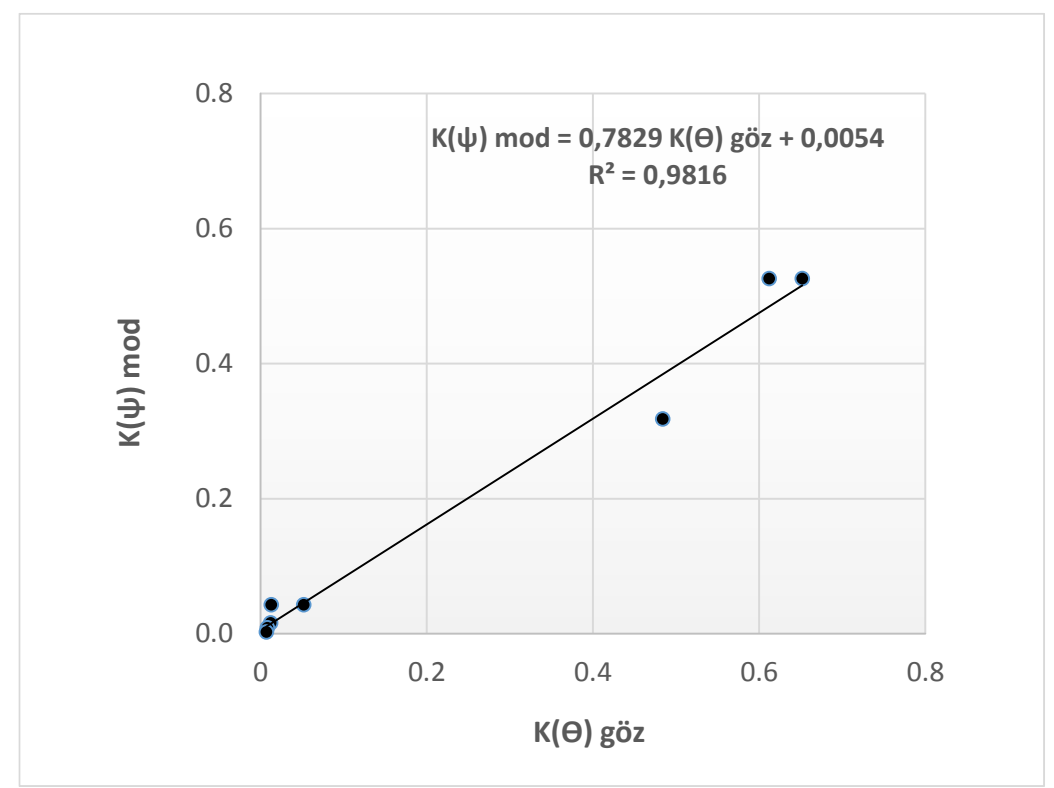

Şekil 3. Kullanılan model ile tarla denemesi aşamasında toprağın öngörülen ve ölçülen doymamış hidrolik iletkenliği arasındaki ilişki.

Figure 3. Relationship between the measured and the predicted unsaturated hydraulic conductivity of soil during the field testing phase using the model.

Libardi ve ark. (1980) tarafindan incelenen bes toprağın doymamış iletkenlikleri, önerilen ilişkiler kullanılarak su tutma eğrilerinden tahmin edilmiştir. $\mathrm{Bu}$ uyum, deneysel ve tahmin edilen değerler arasında 0.976 korelasyon katsayısı ile iyi bir uyum yakalamıştır. Bu uyum toprak hidrolik iletkenliğinin, $0.0001 \mathrm{~mm} \mathrm{sa}^{-1}$ ile $0.01 \mathrm{~mm} \mathrm{sa}^{-1}$ arasında ölçülen aralığında yüksek doğrulukta gerçekleşmiştir. Burada, araştırmacılar daha yüksek korelasyon katsayısının nedenini, "laboratuvar koşullarında hidrolik iletkenlik hesaplamaları sırasındaki zayıflık yada uygulama hatalarının, tarla koşullarında ölçümleme sırasındaki köklerin oluşturduğu kanallar ve büyük çatlaklar, makro gözenek akışına bağlı hatalardan daha az olması" olarak göstermişlerdir. $\mathrm{Bu}$ durum ölçüm değerlerini tahminlemede kullanılan denklemlerin teorik varsayımlarına daha yakın hale getirmektedir.

Burada verilen örnekler; sayısal modeller, laboratuvar koşullarında ve ampirik eşitliklere dayalı hesaplanmış verilerin kullanımının önemli ölçüde farklı sonuçlar vereceği de kesindir.

\section{Sonuç}

Toprakların hidrolik iletkenlik değeri doygunluktaki nem içeriğinden uzaklaștıkça hızlı bir șekilde azalmaktadır. Arazi koşullarında toprak su içeriği sürekli değişim gösterdiği için, toprak su dinamiği ve bütçesi çalışmalarında hidrolik iletkenliğin toprağın matrik emişine veya nem düzeyine bağlanması ve modellenmesi gerekmektedir. $\mathrm{Bu}$ bağlamda Eşitlik (3)'de de görüldüğü gibi, toprak su içeriğinin azalması (matrik emişin artması), hidrolik iletkenliğin de ortamdaki duruma göre doygunluktan uzaklaşacağının matematik ifadesini yansıtmaktadır. Yapılan çalışmada serbest drenaj yöntemi ile toprak neminin azalmasıyla, hidrolik iletkenlik değerinin düştüğü görülmektir. Arıklı serisinin hidrolik iletkenliği 0.652 $\mathrm{cm} \mathrm{sa}^{-1}$ 'ten $0.007 \mathrm{~cm} \mathrm{sa}^{-1}$ ye düşmüştür.

Araştırmadaki asıl amacımız arazide yerinde ölçülen hidrolik iletkenlik ile laboratuvarda ölçülen hidrolik iletkenliğin karşılaştırılması olmuştur. Toprak suyunun dinamiğini çalışacak kişiler hidrolik iletkenliği kullanacaksa bunun arazide ölçülmesi gerekmektedir. Çünkü arazide yerinde yani bozulmamış toprakta su akışı ile laboratuvar ortamına taşıdığımız bozulmamış örnekte düşen su yükünde ölçülen hidrolik iletkenlik değerleri çok farklılık göstermekte ve laboratuvar ortamında ölçülen hidrolik iletkenlik değerleri araziye uygulandığında sıkıntılar çıkarabilmektedir. Yapılan çalışma bunu destekler niteliktedir. Toprak su dinamiği çalışmalarında, ölçümlerin arazide yerinde yapılması gerekmektedir. Aksi takdirde laboratuvar ortamında ölçülen değerlerin araziye uygulanmasında sikıntılar doğabilmektedir. Laboratuvar ortamında çalışma yapılması durumunda Bondarenko ve ark. (1982)'nın kullandığg 1 eşitlik ile arazi çalışmalarında doymamış koşullarda hidrolik iletkenlik değerlerine ulaşılabilmekte ya da tahmin edilebilmektedir.

Toprak hidrolik iletkenlik modellerinin geliştirilmesi üzerine gelecekteki araştırmalar, nispeten yüksek toprak nemi içeriklerinde $\mathrm{K}(\Theta)^{\prime}$ 'yi etkileyen spesifik toprak fiziksel parametrelerine ayrıntılı olarak odaklanmalıdır. Temel toprak yapısını ve gözenek geometrisi içeren pedotransfer fonksiyonlarının geliştirilmesi, daha doğru ölçeklendirme faktörlerinin elde edilmesine yardımcı olacaktır.

\section{Kaynaklar}

Ahmadi SH, Sepaskhah AR (2012) Prediction of saturated hydraulic conductivity of compacted soils using empirical scaling factors. Archives of Agronomy and Soil Science 58: 1303-1316.

Ahmadi SH, Sepaskhah AR, Fooladmand HR (2015) A simple approach to predicting unsaturated hydraulic conductivity based on empirically scaled microscopic characteristic length. Hydrological Sciences Journal 60(2): 326-335.

Ahuja LR, Naney JW, Nielsen DR (1991) Scaling soil water properties and infiltration modeling. Soil Science Society of America Journal 48: $970-973$

Al-Sulaiman M, Aboukarima A (2016) Prediction of unsaturated hydraulic conductivity of agricultural soils using artificial neural network and c\#. Journal of Agriculture and Ecology Research International 5(4): 1-15. 
Black CA (1965) Methods of soil analysis part-II. America Society of Agronomy-Inc., Publisher Madison, Wisconsin, USA, pp. 13721376.

Blake GR, Hartge KH (1986) in ed.: A. Klute, Methods of Soil Analysis, Part 1, Physical and Mineralogical Methods, Agronomy. Monograph 9, American Society of Agronomy and Soil Science Society of America, Madison WI, pp. 363-375.

Bondarenko HF, Jukovsky EE, Muskın IG, Nerpin SV, Poluektov RA, Uskov IB (1982) Simulation of Agroecosystem Productivity, Russia.

Bouyoucos GJ (1951) A recalibration of the hydrometer method for making mechanical analysis of soils. Agronomy Journal 43: 435438.

Comegna V, Damiani P, Sommella A (2000) Scaling the saturated hydraulic conductivity of a vertic ustorthens soil under conventional and minimum tillage. Soil and Tillage Research 54: 19.

Cook FJ (1991) Calculation of hydraulic conductivity from suction permeameter measurements. Soil Science, pp. 321-325.

Danielson RE, Sutherland PL (1986) Porosity. Methods of Soil Analysis Part 1, Physical and Mineralogical Methods Second Edition, pp. 443-462.

Finsterle S, Faybishenko B (1999) Inverse modeling of a radial multistep outflow experiment for determining unsaturated hydraulic properties. Water Resources Research 2: 431-444.

Gemalmaz E (1992) Örneklenen toprak hacmi ile arazide ölçülen hidrolik iletkenlik değerlerinin varyansı arasındaki ilişki, IV. Ulusal Tarımsal Yapılar ve Sulama Kongresi Bildirileri, Atatürk Üniversitesi Ziraat Fakültesi Tanmsal Yapılar ve Sulama Bölümü. Erzurum.

Kırda C, Sarıyev A (2002) Toprak Fiziği. Çukurova Üniversitesi Ziraat Fakültesi Genel yayın No: 245, Ders Kitapları Yayın No: A-79, Adana.

Klute A (1986) Water Retention: Laboratory Methods. In: Methods of Soil Analysis, Part 1, Physical and Mineralogical Methods. (Ed: A. Klute) Agronomy. Monograph. American Society of Agronomy and Soil Science Society of America, Madison WI. pp. 635-662.

Klute A, Dirksen C (1986) in ed.: A. Klute, Methods of Soil Analysis, Part 1, Physical and Mineralogical Methods, Agronomy. Monograph. 9, American Society of Agronomy and Soil Science Society of America, Madison WI, pp. 687-734.

Kosugi K, Hopmans JW (1998) Scaling water retention curves for soils with lognormal pore-size distribution. Soil Science Society of America Journal 62: 1496-1505.

Lebeau M, Konrad JM (2010) A new capillary and thin film flow model for predicting the hydraulic conductivity of unsaturated porous media. Water Resources Research 46: W12554 doi: 10.1029/2010WR009092.

Libardi PL, Reichardt K, Nielsen DR, Biggar JW (1980) Simple field methods for estimating soil hydraulic conductivity. Soil Science Society of America Journal 44: 3-7.

McLean EO (1982) Soil pH and lime requirement. In Page, A. L., R. H. Miller and D. R. Keeney (eds.) Methods of soil analysis. Part 2 Chemical and microbiological properties. (2nd Ed.). Agronomy 9: 199-223.

Mermoud A, Xu D (2006) Comparative analysis of three methods to generate soil hydraulic functions. Soil Tillage Research 87: 89-100.

Mohammadi MH and Vanclooster M (2011) Predicting the soil moisture characteristic curve from particle size distribution with a simple conceptual model. Vadose Zone Journal 10: 594-602.
Mualem Y (1976) A new model for predicting the hydraulic conductivity of unsaturated porous media. Water Resources Research 12: 513-520.

Nandagiri L, Prasad R (1996) Field evaluation of unsaturated hydraulic conductivity models and parameter estimation from retention data. Journal of Hydrology 179: 197-205.

Nath A, Chattopadhyay PK (2007) Optimization of oven toasting for improving crispness and other quality attributes of ready to eat potato-soy snack using response surface methodology. Journal of Food Engineering 80(4): 1282-1292.

Özcan H, Akbulut C (2006) 1. Uzaktan Algılama-CBS Çalıștay ve Paneli-2006 (UZAL-CBS-2006), İstanbul Teknik Üniversitesi. http://uzalcbs.org/wpcontent/uploads/2016/11/2006_16.pdf.19/06/2 019.

Öztekin T, Cemek B, Brown L (2007) Pedotransfer functions for the hydraulic properties of layered soils. Gaziosmanpaşa Üniversitesi Ziraat Fakültesi Dergisi 24(2): 77-86.

Poluektov RA (1991) Simulation of Agroecosystem Dynamics, Gidrometoizadat, St.Petersburg, Russia, pp. 312.

Rahimi A, Sepaskhah AR, Ahmadi SH (2011) Evaluation of different methods for prediction of saturated hydraulic conductivity of tilled and untilled soils. Archives of Agronomy and Soil Science 57: 899914.

Reichardt K, Portetan-Filho O, Libardi PL, Bacchi OS, Moraes SO, Oliveria JCM, Fallerios MC (1998) Critical analysis of the field determination of soil hydraulic conductivity functions using the flux-gradient approach. Soil Tillage Research 48: 81-89.

Rose CW, Stem WR, Drummond JE (1965) Determination of hydraulic conductivity as a function of depth and water content for soil in situ. Australian Journal of Soil Research 3: 1-9.

Sadeghi M, Ghahraman B, Davary K, Hasheminia SM, Reichardt K (2011) Scaling to generalize a single solution of Richards' equation for soil water redistribution. Scientia Agricola (Piracicaba, Brazil) 68: 582-591.

Sarıyev A, Polat V, Müjdecı M, Yusufova M, Akça E (2007) Mathematical modelling of soil hydraulic properties and numerical analyses of moisture dynamic. Asian Journal of Chemistry 19(4): 3125-3131.

Schlichting E, Blume HP (1966) Bodenkundliches praktikum. Verlag Paul Paney, Hamburg und Berlin, pp. 121-125.

Smedema LK, Rycroft DW (1988) Land Drainage. B T Batsford Ltd. London, ISBN 0-7134-6045-8.

Talsma T (1985) Prediction of hydraulic conductivity from soil water retention data. Soil Science 140: 184-188.

Tokunaga, TK (2011) Physicochemical controls on adsorbed water film thickness in unsaturated geological media. Water Resources Research 47: W08514, doi: 10.1029/2011WR010676.

Tyler SW, Wheatcraft SW (1989) Application of fractal mathematics to soil water retention estimation. Soil Science Society of America 53: 987-996.

United State Salinity Laboratory Staff (1954) Diagnosis and Improvement of Soil Saline and Alkaline Soils. Agricultural Handbook No: 60.

van Genuchten MT (1980) A closed-form equation for predicting the hydraulic conductivity of unsaturated soils. Soil Science Society of America Journal 44: 892-898. doi: 10.2136/ sssaj1980.03615995004400050002x.

Watson KK (1966) An instantaneous profile method for determining the hydraulic conductivity of unsaturated porous materials. Water Resources Research 2: 709-715. 
Yakupoğlu T, Şişman AÖ, Karagöktaş M, Demir ÖF (2013) Toprakların doygun koşullardaki hidrolik iletkenlik değerlerinin pedotransfer eşitlikler ile tahminlenmesi. Süleyman Demirel Üniversitesi Ziraat Fakültesi Dergisi 8(1): 84-92.

Youngs EG (1987) Estimating hydraulic conductivity values from ring infiltrometer measurements. European Journal of Soil Science 38(4): 623-632.

Zhang ZF, Andy L, Gee GW (2003) Estimating soil hydraulic parameters of a field drainage experiment using inverse techniques. Vadose Zone Journal 2: 201-211.
Zhuang J, Nakayama K, Yu GR, Miyazaki T (2000) Scaling of saturated hydraulic conductivity: A comparison of models. Soil Science 165: 718-727. doi: 10.1097/00010694-200009000-00005.

Zhuang J, Nakayama K, Yu GR, Miyazaki T (2001) Predicting unsaturated hydraulic conductivity of soil based on some basic soil properties. Soil and Tillage Research 59: 143-154. doi: 10.1016/S0167-1987(01)00160-X. 